\title{
De la compasión a la capitalización de recursos. Los centros de salud confesionales españoles en el marco de la cooperación sanitaria española en Guinea Ecuatorial
}

\author{
Alvar Jones Sánchez ${ }^{1}$
}

Recibido: 25 de noviembre de 2015 / Aceptado: 24 de abril de 2016

Resumen. El presente artículo recoge las principales etapas de la cooperación sanitaria española en Guinea Ecuatorial, prestando especial atención a los factores que han situado a los centros de salud de las congregaciones españolas como las alternativas terapéuticas más competitivas del mercado. Las congregaciones, elemento clave en el proceso de colonización, han sido movilizadas de nuevo para responder a las veleidades neocoloniales del estado Español.

Combinando una perspectiva socio-histórica y etnográfica, se cuestiona la calidad de la intervención de los centros confesionales, no tanto desde el punto de vista técnico, sino respecto a las implicaciones de la construcción de archipiélagos sanitarios para la consolidación del incipiente sistema sanitario. Las tensiones entre los objetivos misioneros, marcadamente asistenciales, y los planteamientos actuales de desarrollo evidencian las ambigüedades de la cooperación española en Guinea. La ayuda, presentada como un imperativo moral, ha movilizado significados flexibles y a veces contradictorios que es preciso desentrañar. Una reflexión sobre los objetivos manifiestos y aquellos no formulados que rigen las relaciones neocoloniales, permite aprehender la distancia entre los objetivos planteados y la consecución de resultados.

Palabras clave: Guinea Ecuatorial; cooperación española al desarrollo; congregaciones religiosas españolas; sistema sanitario guineano.

\section{[en] From Compassion to the Capitalization of Resources. Spanish Confessional Health Centers within the scope of Spanish Health Cooperation with Equatorial Guinea}

\begin{abstract}
This article presents the main stages of Spanish health cooperation in Equatorial Guinea, focusing on the factors that have established the Spanish congregations' health centers as the market's most competitive therapeutic alternatives. Congregations, a key element in the colonization process, have been mobilized again in order to match the neocolonial whims of the Spanish State.

Combining a socio-historical and an ethnographic perspective, this article questions the quality of the activity of confessional health centers, not so much from the technical point of view as from the perspective of the implications that the construction of health archipelagos may have in the consolidation of the incipient health care system. The tensions between missionary goals, markedly assistanceoriented, and the current approaches to development, show the ambiguities of Spanish cooperation in Equatorial Guinea. Aid, presented as a moral imperative, has mobilized flexible and sometimes contradictory meanings which must be unraveled. A reflection on revealed goals and unformulated aims governing neo-colonial relations will enable us to understand the distance between the aims and the achievement of results.
\end{abstract}

\footnotetext{
$1 \quad$ Universidad de Castilla-La Mancha alvar.js@hotmail.com
} 
Keywords: Equatorial Guinea; Spanish development aid; Spanish religious congregations; Equatorial Guinea health system.

Sumario: 1. Introducción. 2. La gestación de la supremacía de los centros confesionales en el mercado de la salud guineano. 2.1. El imperio sanitario prestado (1980-1993). 2.2. El declive del imperio: "redimensionar" la cooperación española con Guinea Ecuatorial (1994). 2.3. El monopolio de las congregaciones en la adjudicación de subvenciones de la cooperación española (1992-2013). 3. Los centros de salud confesionales en el mercado formal de la salud. 3.1. Archipiélagos sanitarios. 3.2. Los efectos inopinados de una competitividad exitosa. 4. Definiciones encontradas de la ayuda. 4.1. La reformulación reciente de la cooperación sanitaria española en Guinea. 4.2. De FERS a FRS. 4.3. ¿Congregación versus cooperación? 5. Conclusión: el sempiterno debate en torno a la AOD (Ayuda Oficial al Desarrollo) española en Guinea Ecuatorial. 6. Referencias bibliográficas.

Cómo citar: Jones Sánchez, A. (2016). De la compasión a la capitalización de recursos. Los centros de salud confesionales españoles en el marco de la cooperación sanitaria española en Guinea Ecuatorial, en Revista de Antropología Social 25(2), 317-340.

“Analizar una política es hacerse un conjunto de preguntas finalmente bastante simples - aquellas relativas a los objetivos perseguidos, a los intereses servidos, a las alianzas establecidas, y a los instrumentos utilizados-, que desembocan eventualmente sobre otras, menos simples: las del desajuste eventual entre los objetivos presentados y los resultados alcanzados, y aquella de los efectos imprevistos, si no perversos, que libran a menudo el sentido real de una política."2

\section{Introducción}

La oferta de salud de las congregaciones religiosas españolas en Guinea Ecuatorial conforma una de las alternativas sanitarias más importantes del país. No es una situación aislada. En numerosos países del África subsahariana, los servicios sanitarios confesionales constituyen uno de los principales pilares de los sistemas nacionales de salud ${ }^{3}$.

Si bien los estudios sobre la labor de las Organizaciones No Gubernamentales (ONGs) en el campo de la ayuda al desarrollo son hoy abundantes ${ }^{4}$, el interés por el papel que desempeñan las entidades confesionales en la industria del desarrollo es reciente ${ }^{5}$ y aún inexistente en España. Asimismo, los trabajos sobre la historia re-

Lautier (2001: 169) Traducción propia.

3 Berche ya destacaba en 1985 que entre el 30\% y el 50\% de los servicios sanitarios de los 7 países africanos en los que llevó a cabo su investigación estaban dispensados por estructuras confesionales (Berche, 1985: 86). Más recientemente, el informe de la Organización Mundial de la Salud (OMS) “Appreciating Assets: Mapping, Understanding, Translating and Engaging Religious Health Assets in Zambia and Lesotho", publicado en 2006, estimaba que según los países, entre el 30 y el 70\% de las infraestructuras de salud en el continente africano estarían gestionadas por organizaciones confesionales.

4 Véase por ejemplo Campos Serrano (2005), Picas Contreras (2006 a/b) y Nerín (2011).

5 Véanse por ejemplo los trabajos pioneros de Berche (1985) y más recientemente de Gruénais (2004), Duriez Mabille et Rousselet (2007), Hovland (2008), Kaag y Saint-Lary (2011), Haynes (2013) y Fountain (2013). 
ciente de Guinea Ecuatorial son escasos, y tienden a dejar al margen la intervención de las congregaciones religiosas españolas en el país ${ }^{6}$.

El presente artículo, pretende abordar el papel de las congregaciones religiosas en el arsenal desplegado por la cooperación sanitaria española en Guinea Ecuatorial. Las congregaciones, elemento clave en el proceso de colonización, han sido movilizadas de nuevo para responder a las veleidades neocoloniales del estado Español en el país africano. Interesarse por el lugar de los centros confesionales en el sistema de salud guineano, y por el recorrido en el país de las congregaciones españolas que los gestionan, permite descifrar las estrategias e intereses que han guiado la intervención de la cooperación sanitaria española con Guinea.

Tras cerca de 35 años de intervención directa e ininterrumpida en el sector salud, los resultados alcanzados por la cooperación española son frágiles e insuficientes a tenor de los objetivos planteados, del tiempo, esfuerzos y medios invertidos. Estas consideraciones plantean la necesidad de discutir el tradicional consenso sobre la labor, poco cuestionada, de la cooperación sanitaria española en Guinea, y especialmente de aquella vinculada a los centros confesionales. El enunciado humanitario, cómodo y consensual, apela al imperativo de prodigar atención a quienes más lo necesitan. Ha movilizado sin embargo significados flexibles y a veces contradictorios que es preciso desentrañar. Dan cuenta de los aspectos más problemáticos de la intervención española en el país.

La primera parte del artículo se detiene sobre los factores históricos y financieros que han erigido los centros confesionales en las alternativas más competitivas del mercado formal de la salud. Este recorrido apela necesariamente al desentendimiento del Estado guineano respecto a la gestión de los sectores sociales, a la evolución de las relaciones entre España y Guinea, y a la utilización estratégica de la ayuda humanitaria en virtud de intereses neocoloniales.

En la segunda parte, se sitúa la oferta de los centros confesionales en el mercado de la salud ${ }^{7}$. Se abordan los aspectos que fundamentan para sus usuarios, su capacidad de atracción en relación con las demás alternativas del sector público. Pero también se recogen las repercusiones a veces problemáticas del éxito de los centros confesionales sobre la incipiente oferta pública. A menudo obviadas, traducen una acepción de la ayuda en términos asistenciales, en detrimento de criterios de viabilidad ligados a la consolidación del sistema sanitario guineano.

La tercera parte del artículo recoge los intentos recientes de la cooperación sanitaria española en Guinea por superar una perspectiva asistencialista. Persisten sin embargo contradicciones entre los paradigmas actuales sobre desarrollo suscritos por la cooperación española, que contemplan mecanismos de empoderamiento de las estructuras locales y el apoyo financiero que se ha venido brindando a las congregaciones hasta fechas recientes. Las tensiones entre los propósitos misionarios y

6 Contrasta con los numerosos trabajos que abordan el papel de las misiones cristianas durante la empresa colonial española en el golfo de Guinea. Véase por ejemplo Creus (2007), Nerín (2008), Vilaró I Güell (2009, 2010), Castillo-Rodríguez (2013).

7 En el presente artículo, se abordará esencialmente el papel de los 6 centros confesionales españoles integrados en la red nacional de atención primaria de Salud. Existen otras estructuras sanitarias gestionadas o apoyadas por congregaciones españolas en Guinea Ecuatorial: la leprosería de Micomeseng, órgano público apoyado por la misión católica de las Hijas de la Caridad desde principio de los años ochenta; el Centro de Día Agustín López Manjón, creado en 2001, también especializado en la enfermedad de Hansen; y el centro de salud mental San Benito Menni de Bata, inaugurado en 2012, a cargo de las Hermanas Hospitalarias del Sagrado Corazón de Jesús. 
aquellos de desarrollo traducen concepciones encontradas de la ayuda, ligadas unas y otras, a intereses contrapuestos. Dan cuenta en última instancia de la distancia entre los objetivos planteados y los resultados alcanzados.

Este trabajo se fundamenta sobre las observaciones y entrevistas realizadas en el marco de una investigación etnográfica llevada a cabo en $2011^{8}$. También saca partido de los documentos de seguimiento y evaluación generados estos últimos años por la Fundación de Religiosos para la Salud (FRS), una de las entidades más beneficiadas por la cooperación española en Guinea.

\section{La gestación de la supremacía de los centros confesionales en el mercado de la salud guineano}

\subsection{El imperio sanitario prestado (1980-1993)}

Presionado por la comunidad internacional, el Estado Español otorgaría la independencia a su antigua colonia el 12 de octubre 1968. Las relaciones entre el nuevo estado independiente y la antigua metrópolis se tensarían rápidamente. Al mismo tiempo, el Estado embrionario pronto se tornaría en un régimen marcado por la arbitrariedad y el terror. Los once años de gobierno de Francisco Macías Nguema dejaron el país exangüe y sin recursos. En el ámbito sanitario no quedó ningún resquicio del sistema implantado por las autoridades coloniales ni de cualquier tipo de organización de atención sanitaria institucionalizada' 9

Tras el golpe de estado de 1979, las nuevas autoridades solicitarían la ayuda de la antigua metrópolis para la reconstrucción del país. El Estado Español desplegaría un dispositivo asistencial de envergadura. En el ámbito sanitario, se enviarían desde España un importante contingente de médicos de diferentes especialidades encargado de rehabilitar y gestionar las infraestructuras hospitalarias heredadas de la época colonial. Serían secundados por cuarenta religiosas con perfil sanitario, de catorce congregaciones diferentes. Asumirían labores asistenciales, paramédicas y la gestión logística de los centros.

A lo largo de la década de los ochenta, la gestión y el desarrollo del sector sanitario fue en su gran mayoría asumido por la cooperación española. Tanto la toma de decisiones, como la puesta en ejecución de las principales orientaciones estratégicas,

8 En el 2011, visité varios espacios de terapia en Bata, capital de la región continental de Guinea Ecuatorial con el fin de reflexionar acerca de las representaciones y modalidades de uso de los diferentes recursos existentes en la ciudad. El presente artículo saca partido de las entrevistas realizadas entonces a dos responsables ministeriales, 3 gestores de centros de salud, 5 religiosas con un largo recorrido en el país y 3 consultores de la Fundación de Religiosos para la Salud (FRS). También mantuve numerosos encuentros formales e informales con cooperantes en activo o retirados que, desde 1980 hasta la actualidad, han participado en la implementación del sistema sanitario guineano.

9 Las disposiciones sanitarias más significativas fueron tomadas desde fuera. El distanciamiento de Macías con los países occidentales tras la independencia, propició el acercamiento de Guinea Ecuatorial con el bloque del Este. En este marco, numerosos guineanos fueron becados durante la década de los setenta en la antigua Unión Soviética y en China para cursar estudios superiores, incluidos de medicina. China por otra parte, envió brigadas sanitarias que desempeñaron su labor asistencial (y siguen haciéndolo) en los Hospitales de Bata y Malabo. No obstante, no se extendieron en los distritos, ni tampoco se involucraron en la planificación y gestión nacional del sistema sanitario. 
se gestaron desde la diáspora expatriada de la antigua metrópolis. "El Ministerio de salud éramos nosotros", señala un antiguo cooperante español, resumiendo quizás con bastante exactitud, 13 años ininterrumpidos de intervención ${ }^{10}$. Los médicos laicos españoles, con el apoyo de las religiosas, marcaron los ejes de la intervención, siendo los artífices de la rehabilitación de los servicios hospitalarios y de la implementación a partir de 1985 de las primeras balizas de la estrategia nacional de Atención Primaria (Jones Sánchez, 2013, 2016: 34-39).

La dinámica entonces implementada generaba un tutelaje español de los sectores sociales del país. Conllevaría escasos procesos de refuerzo y autonomización de las estructuras sanitarias locales. Por parte de las autoridades guineanas, la delegación del sector sanitario a los interventores externos, y en especial a la cooperación española, respondía a un desinterés estratégico. Junto a los demás sectores sociales, el ámbito sanitario era considerado de escaso rendimiento económico, simbólico y político. No constituía, para las autoridades en ejercicio, un ámbito de importancia para el mantenimiento y la reproducción de las estructuras del poder ${ }^{11}$.

Resulta asombroso que durante los primeros años de la intervención, no hubiese mecanismos de planificación, una formulación tangible de objetivos que alcanzar, o herramientas de supervisión que permitiesen el seguimiento de la actuación. El primer sistema de información respecto a la labor implementada se pondría en pie en 1990, 10 años después de la llegada al país de la cooperación española ${ }^{12}$. Tampoco se llevaron a cabo evaluaciones respecto al impacto de la cooperación sanitaria española en Guinea. La perspectiva desarrollada, y aún vigente hasta fechas recientes, resultaba esencialmente de carácter asistencialista. Manifestaba escasos miramientos por los resultados alcanzados en la medida en la que no se perseguía tanto la efectividad, sino la visibilidad.

La gratuidad de los medicamentos practicada por la cooperación española en los centros que tutelaba, es especialmente ilustrativa al respecto. Esta práctica, si bien participaba del prestigio y de la visibilidad de España en el exterior, resultaba contraproducente. Contravenía las recomendaciones internacionales emitidas por la OMS en Bamako (1987) que preconizaban la recuperación de costos mediante la tarificación de la atención, para asegurar unos ingresos a los centros sanitarios que permitiesen su viabilidad. La gratuidad también generaba hábitos y expectativas entre la población que el Estado guineano no podría satisfacer tras el cese de la ayuda. Precisamente, la ausencia de planteamientos acerca de la viabilidad de la interven-

10 Agustín Blanco Moro, uno de los máximos responsables de la cooperación española en el país, escribe, forzando quizás el trazo, que durante aquel periodo "los guineanos no pusieron otra cosa que los enfermos" (Blanco Moro, 1997: 115). También señala que la cooperación española ni tan siquiera comunicaba "las altas y las bajas del personal [español] ni los lugares de destino de cada cual” (Blanco Moro, 1997: 122). Estos procedimientos traducen la absoluta libertad y despreocupación con la que operaba la cooperación española respecto a las autoridades locales.

11 Esta perspectiva ha cambiado estos últimos años. Tras el descubrimiento de importantes yacimientos de petróleo en los noventa, las rentas del crudo han dado pié a la revisión por parte del Estado guineano, de su papel en el ámbito sanitario. Ha irrumpido estos últimos años en el sector, pero no tanto como gestor, sino como mecenas. La salud alberga hoy para las estructuras del poder una nueva dimensión, vinculada a la economía de la ostentación. Se han edificado grandes complejos sanitarios privados de alta gama, económicamente inaccesibles para la mayor parte de la población (Jones Sánchez, 2016: 59-65).

12 La cooperación sanitaria española genera boletines trimestrales a partir de 1990. No recogen sin embargo datos epidemiológicos que hubiesen permitido valorar el impacto de la cooperación sobre la mortalidad y morbilidad. Se centraban en las actividades llevadas a cabo, el número y el perfil de las consultas atendidas. 
ción, ha caracterizado una ayuda que se ha ejercido sin la intencionalidad manifiesta de dejar de ser necesaria.

Las carencias de la cooperación no solo respondían a la falta de experiencia del Estado español, quien emprendía su primer gran reto en la materia ${ }^{13}$. Los intereses españoles en el país estaban ligados a la manifestación explícita y tangible de un compromiso de responsabilidad social. Las veleidades neocoloniales no solo perseguían el mantenimiento de la "lengua" y "cultura" española ${ }^{14}$, sino también el acceso a las principales materias primas (madera, cacao), en un contexto en el que la probabilidad de que hubiese importantes yacimientos de petróleo era más que una sospecha. Según Blanco Moro (1997: 132), uno de los máximos responsables de la intervención durante los primeros años, al Ministerio de Sanidad —entonces a cargo de la cooperación sanitaria_-, le "bastaba saber con que estábamos allí" sin interes manifiesto por lo que se hacía. Más atenta a la visibilidad que a la consecución de resultados, la ayuda española al desarrollo perseguía generar una renta simbólica canjeable en el terreno político. No obstante, las rentas de la dependencia ligada a la cooperación no lograrían trasladarse a otras esferas del poder. Nunca se transformaron en un ascendente determinante en el ámbito político y económico ${ }^{15}$.

\subsection{El declive del imperio: "redimensionar" la cooperación española con Guinea Ecuatorial (1994)}

Todos los observadores concuerdan sobre el extremo grado de dependencia de Guinea Ecuatorial respecto a la ayuda externa a lo largo de los ochenta. Ésta constituía a finales de la década más del 54\% del PIB del país (Larrú, 2010). Según Gorozpe (2006: 3), hasta el año 1994, la ayuda externa mantenía un gasto en personal que era superior al del propio gobierno guineano. Según otros observadores, más del $80 \%$ del sector sanitario había llegado a depender de la ayuda externa a lo largo de este periodo. Abaga Edjang (1997) recuerda, por su parte, que el sector sanitario había canalizado la mayor parte de la ayuda en Guinea Ecuatorial, alcanzando a principios de los noventa el 19\% de la ayuda externa. La ayuda al desarrollo constituía entonces el sustento más importante del país y el principal pilar de las estructuras sociales.

La dependencia del sistema sanitario guineano en relación con la ayuda externa, ha tenido consecuencias nefastas. Desencadenaría un apagón sanitario, cuando en 1994, España redujo repentinamente el volumen de su ayuda: la expulsión del cónsul español de Bata y consecuentes tensiones diplomáticas entre España y Guinea Ecuatorial, darían pié a la reducción a la mitad de la ayuda española en el país ${ }^{16}$. En

13 El Estado Español disponía hasta entonces de escasos antecedentes en cooperación. De hecho, hasta finales de los años setenta, España era aún considerada como un país en vía de desarrollo (Pozuelo Mascaraque, 1991: 205). La inexperiencia española era reconocida por el propio Ministerio de Asuntos Exteriores, Marcelino Oreja Aguirre, quien expresó el deseo de que Guinea fuese "el modelo y también la escuela de nuestra política de cooperación con otros pueblos" (Roig, 1993). Los mecanismos de ayuda al desarrollo españoles empiezan a institucionalizarse a mediados de los ochenta, derivando en 1988 en la creación de la Agencia Española de Cooperación Internacional (AECI).

14 Según los propios términos del ministro de asuntos exteriores español en 1981 (Roig, 1993).

15 Gorozpe (1994: 81) señala a tal efecto, que "el miedo de los nacionalistas españoles a que Guinea caiga en la órbita francófona ha facilitado un amplio margen de maniobra a la dictadura". Ha permitido el incumplimiento por parte de Guinea de los numerosos tratados bilaterales, sin arriesgar las cuantiosas y permanentes dotaciones españolas dedicadas a la ayuda al desarrollo.

16 Las elecciones legislativas de 1993, las primeras desde la independencia en 1968, no fueron reconocidas por el 
el campo sanitario se tomarían medidas drásticas, retirando en pocas semanas, los principales recursos materiales, humanos y financieros sobre los que se sustentaba la red hospitalaria.

Las razones que motivaron la reducción de la ayuda española no solo eran de orden diplomático. El despliegue de la ayuda para afirmar y consolidar la influencia española en Guinea había resultado un fracaso. Si bien Guinea representaba el 55\% de la cooperación española en África subsahariana, seguía constituyendo una parte marginal del comercio exterior español (Gorozpe, 1994: 81). Al parecer, la situación contractual de los médicos cooperantes que trabajaban entonces en Guinea también habría sido un elemento determinante ${ }^{17}$.

La versión oficial de las autoridades españolas aludiría sin embargo a la necesidad de "redimensionar su cooperación" con el país, en la medida en la que la intervención "se había hecho cargo de responsabilidades propias del gobierno de Guinea Ecuatorial". Se argumentaba, en este sentido, la necesidad de mantener solo aquellas intervenciones "de carácter estrictamente humanitario"18.

Bajo la resignificación de la cooperación sanitaria en términos "humanitarios", se adoptaron dos decisiones claves que determinarían el devenir del paisaje sanitario guineano: el cese de los principales mecanismos de apoyo destinados a los hospitales, y la canalización de la ayuda designada como "humanitaria" hacia las congregaciones religiosas españolas presentes en el país.

En cuanto a la primera, es preciso señalar que los servicios públicos gestionados por la cooperación española efectuaban hasta el momento la mayor parte de las prestaciones sanitarias institucionalizadas. En este sentido, la súbita repatriación de los 25 médicos españoles que aún desempeñaban su labor en el país (en un contexto en el que escaseaban los médicos guineanos), el cese abrupto de las dotaciones que permitían el mantenimiento y funcionamiento de las infraestructuras sanitarias y, de forma general, el desmantelamiento del sistema hospitalario erigido por los cooperantes españoles desde 1980, desencadenarían una grave crisis sanitaria. Se traduciría en la siguiente década en el empeoramiento de los índices sanitarios del país ${ }^{19}$.

Estado español, que al igual que gran parte de la comunidad internacional, manifestaría su disconformidad con la falta de transparencia en el proceso electoral. El periodo de creciente tensión entre ambos países culminaría con la expulsión del cónsul de Bata, acusado por el régimen de "injerencia en los asuntos internos del país". Frente a la expulsión de su representante, Madrid replicó con la retirada del embajador en Malabo. También se decidió suspender la renovación del Plan Marco de Cooperación entre ambos países y reducir a la mitad la Ayuda Oficial al Desarrollo dedicada al país.

17 Los médicos españoles destinados a Guinea Ecuatorial constituían el único colectivo que no se ajustaba todavía a los nuevos parámetros de la cooperación. Directamente contratados por el Ministerio de Asuntos Exteriores español, eran funcionarios del Estado. A principios de los noventa, se operó un cambio de paradigma en la cooperación internacional. Ya no serían los estados del norte quienes gestionarían y ejecutarían directamente la ayuda. A partir de entonces, la ayuda se canalizaría mediante convocatorias públicas para las ONG, quienes serían las encargadas de ejecutar los proyectos. Según numerosos médicos interrogados, la inadecuación de su situación contractual respecto a los nuevos paradigmas de la ayuda sería el verdadero motivo de la reformulación de la cooperación española. Las desavenencias diplomáticas habrían constituido un pretexto para dar por finalizada su contratación. Las alegaciones en torno al contencioso diplomático para argumentar el abrupto final de su misión no fue suficiente para evitar el juicio que algunos entablaron (y ganaron) al Estado español por despido improcedente.

18 Así lo manifestaba el embajador español en Guinea en su comparecencia en el Congreso de los Diputados el 9/02/1994.

19 Según los datos del Banco Mundial publicados por CDES (2009), entre 1996 y 2006 el número de niños que sobrevivieron al primer año de vida descendió de 897 a 876 por mil. Aquellos que rebasaron los cinco años, bajó de 830 a 797 por mil. 
La segunda decisión suponía designar las actividades llevadas a cabo por las congregaciones españolas en atención primaria como "ayuda humanitaria", y orientar el apoyo financiero en consecuencia. La década de los ochenta constituyó para las congregaciones un periodo de prospección para evaluar las posibilidades fundacionales existentes en el país. Por ello, si bien las religiosas asistían a los médicos españoles, asumiendo tanto labores asistenciales como de organización de la atención, las congregaciones irían despejando, entre 1988 y 1994, campos de intervención propios. Fundarían seis centros privados de salud de atención primaria, que concentran desde entonces las principales actividades de las religiosas sanitarias en el país ${ }^{20}$. Desligándose de la asistencia hospitalaria y abogando por el apoyo a las estructuras confesionales, la ayuda española operaba un desplazamiento de la intervención, del centro a la periferia, del hospital al centro de salud, y de lo público a lo privado.

Se gestaba un sistema a dos velocidades. Mientras los centros gestionados y apoyados por las religiosas se beneficiaban de un flujo externo de financiación permanente procedente de la antigua metrópolis, y acaparaban gran parte de los pacientes, la insolvencia de las estructuras públicas, tras la súbita "redimensión" de la cooperación española, se plasmaba en espacios vacíos de medicamentos y desertados por los usuarios. Se constituía un nuevo imperio sanitario en torno a la actividad de las congregaciones, ciertamente de menores dimensiones que el de la década anterior, pero en el que permanecía la ausencia de mecanismos de refuerzo, que permitiesen la autonomización de las estructuras sanitarias nacionales.

Apelando a la intervención humanitaria, el gobierno español pretendía situar la intervención en el ámbito moral y subrayar el carácter apolítico de la decisión política, sobre la que se sustentaban la ayuda y los recortes de la misma. Asimismo, invocaba determinados valores ligados a la urgencia y al deber de intervención que beneficiarían de un amplio consenso entre las diferentes fuerzas políticas españo$\operatorname{las}^{21}$. El enunciado humanitario resultaba sin embargo problemático. Atendiendo a determinantes políticos, económicos y diplomáticos, los recortes operaban una elección de necesidades y beneficiarios difícilmente compatibles con la dimensión humanitaria entonces invocada.

\subsection{El monopolio de las congregaciones en la adjudicación de subvenciones de la cooperación española (1992-2013)}

Las modalidades de financiación de los centros confesionales reposan sobre fuentes diversas. Cuentan con el apoyo de las congregaciones a las que pertenecen, con los mecanismos de autofinanciación sustentados en la tarificación de los servicios, y el apoyo del Estado guineano, que asume el salario de parte del personal sanitario.

20 Los centros de salud confesionales gestionados por congregaciones religiosas españolas son los siguientes: el centro de salud de Mokom gestionado por Las hijas de la Caridad; el centro de salud de $\mathrm{M}^{\mathrm{a}}$ Rafols a manos de las Hermanas de la Caridad de Santa Ana; el centro de salud de Angokong, administrado por las Hermanas Hospitalarias; El centro de salud Luis Amigó de Evinayong de las Hermanas Terciarias Capuchinas; El centro de salud de $\mathrm{M}^{\mathrm{a}}$ Gay, propiedad del Instituto de religiosas de San José; El centro de salud de Sampaka (Madre Alfonsa de Savin) gestionado por las Misioneras de la Inmaculada Concepción.

21 Las relaciones con Guinea Ecuatorial han servido en numerosas ocasiones de arma arrojadiza para la oposición española, independientemente de su color. Tanto el Partido Popular como el Partido Socialista han alternado la crítica cuando estaban en la oposición con el mantenimiento de las relaciones bilaterales cuando han gobernado. El mantenimiento de la dimensión humanitaria de la intervención en Guinea Ecuatorial se imponía en 1994 como una referencia moral compartida. 
Asimismo, para gran parte de los centros confesionales españoles, uno de los flujos financieros más significativos ha procedido de la cooperación española.

Desde principios de los noventa, la cooperación española ha canalizado la ayuda al desarrollo a través de ONGs. Este propósito se enmarca en la tendencia de las agencias de cooperación occidentales en los noventa por tratar, al menos en las formas, de despolitizar la ayuda. La implicación de la sociedad civil, de la que las ONGs serían las representantes, pretendía trascender los intereses asociados a las relaciones bilaterales, y superar los reiterados fracasos de las estrategias de desarrollo impulsadas tras la segunda guerra mundial.

Las organizaciones de inspiración religiosa son en general las que más fondos reciben en España (Picas Contreras, 2006: 431). Esta tendencia es aún más acentuada en el contexto ecuatoguineano, en el que las congregaciones religiosas canalizan de forma ininterrumpida, desde más de dos décadas, la mayor parte de los fondos procedentes de la Agencia Española de Cooperación. La Federación de Religiosos para la Salud (FERS), entidad que representa y agrupa diferentes congregaciones españolas operando en el ámbito sanitario en Guinea Ecuatorial, ha sido la principal entidad beneficiaria de los fondos de la cooperación sanitaria española ${ }^{22}$.

\begin{tabular}{|c|c|c|c|c|}
\hline $\begin{array}{l}\text { Organización No } \\
\text { Gubernamental } \\
\text { para el Desarrollo } \\
\text { (ONGD) }\end{array}$ & $\begin{array}{l}\text { importe total } \\
\text { subvenciones } \\
\text { AECID en } €\end{array}$ & $\begin{array}{l}\text { Campos de } \\
\text { actuación en } \\
\text { Guinea Ecuatorial }\end{array}$ & $\begin{array}{l}\text { Años en los que la } \\
\text { ONGD ha percibido } \\
\text { fondos de la AECID }\end{array}$ & $\begin{array}{l}\mathrm{N}^{0} \text { de } \\
\text { subvenciones } \\
\text { adjudicadas }\end{array}$ \\
\hline $\begin{array}{l}\text { Federación Españo- } \\
\text { la de Religiosos de } \\
\text { Enseñanza Titulares } \\
\text { de Centros Católicos } \\
\text { (FERE-CECA) }\end{array}$ & $52.253 .220,45$ & Educación & $1992 ; 1993 ; 1995-2013$ & 38 \\
\hline $\begin{array}{l}\text { Fundación de Reli- } \\
\text { giosos para la Salud } \\
\text { (FRS) }\end{array}$ & $25.067 .300,49$ & Salud & $1992-2002 ; 2004-2013$ & 18 \\
\hline Ayuda en Acción & $4.000 .000,00$ & $\begin{array}{l}\text { Educación } \\
(1.500 .000), \\
\text { salud }(1.500 .00) \text {, } \\
\text { equidad de género } \\
(1.000 .000)\end{array}$ & 2006-2009 & 3 \\
\hline Bosch i Gimpera & $2.216 .172,03$ & Salud & $1995-1998 ; 2000 ; 2001$ & 6 \\
\hline $\begin{array}{l}\text { Proyde Promoción y } \\
\text { Desarrollo* }\end{array}$ & $1.313 .728,32$ & Educación & $1995 ; 1996 ; 1999$ & 4 \\
\hline $\begin{array}{l}\text { Fundación Benito } \\
\text { Menni (FBM)* }\end{array}$ & $899.422,00$ & Salud & 2010 & 1 \\
\hline $\begin{array}{l}\text { Fundación para el } \\
\text { Desarrollo de la En- } \\
\text { fermería (FUDEN) }\end{array}$ & $849.283,00$ & Salud & 2008-2009 & 2 \\
\hline
\end{tabular}

22 La FERS (Federación de Religiosos para la Salud) ha sido hasta 2007 la entidad que ha asumido la labor de coordinación y representación de las congregaciones para la obtención de subvenciones públicas en el ámbito de la cooperación sanitaria. En 2007, sería sustuida por FRS (Fundación de Religiosos para la Salud). Esta evolución será abordada más adelante. 


\begin{tabular}{|c|c|c|c|c|}
\hline $\begin{array}{l}\text { Fundación IN- } \\
\text { TERED. Red de } \\
\text { Intercambio y Soli- } \\
\text { radidad* }\end{array}$ & $656.109,16$ & $\begin{array}{l}\text { Educación } \\
(356.109,16) \text { salud } \\
(300.000)\end{array}$ & $2001 ; 2008$ & 2 \\
\hline $\begin{array}{l}\text { Asociación de } \\
\text { Amigos de Doñana }\end{array}$ & $629.860,69$ & Biodiversidad & $1994 ; 1995 ; 1997$ & 3 \\
\hline Manuel Iradier & $472.152,71$ & Salud & $1994 ; 1995$ & 2 \\
\hline $\begin{array}{l}\text { Organización de } \\
\text { Soliradidad con los } \\
\text { pueblos de África, } \\
\text { Asia y América } \\
\text { Latina (OSPAAAL) }\end{array}$ & $383.380,00$ & Agua y saneamiento & 2007 & 1 \\
\hline Madreselva ONGD* & $311.174,02$ & Educación & $1992 ; 1997 ; 1998$ & 3 \\
\hline $\begin{array}{l}\text { Fundación Hospi- } \\
\text { talaria de la Orden } \\
\text { de Malta en España } \\
\text { (FHOME)* }\end{array}$ & $308.983,67$ & $\begin{array}{l}\text { Salud }(188.217,92) \\
\text { Educación } \\
(120.765,75)\end{array}$ & $2001-2003$ & 3 \\
\hline PROCLADE * & $288.823,67$ & Educación & 2002 & 1 \\
\hline $\begin{array}{l}\text { Médicos sin } \\
\text { Fronteras (MSF) }\end{array}$ & $243.470,00$ & Salud & $1992 ; 1994$ & 3 \\
\hline IEPALA & $196.326,61$ & $\begin{array}{l}\text { Desarrollo integral } \\
\text { y capacitación de } \\
\text { ONG }\end{array}$ & $1997 ; 1998$ & 2 \\
\hline $\begin{array}{l}\text { Proyecto Cultural y } \\
\text { Soliradidad }\end{array}$ & $72.121,45$ & Salud & 1995 & 1 \\
\hline $\begin{array}{l}\text { Jóvenes y } \\
\text { Desarrollo* }\end{array}$ & $72.121,45$ & Salud & 1996 & 1 \\
\hline ASODEGUE & $28.848,58$ & Cultura & 1995 & 1 \\
\hline PROYSO * & $13.500,00$ & Educación & 2010 & 1 \\
\hline
\end{tabular}

Tabla 1. Cuadro resumen del total de las subvenciones de la AECID percibidas por las ONG en Guinea entre 1992 y 2013 desglosado por el monto total adjudicado, el sector de intervención, los años de recepción y el número de subvenciones logradas ${ }^{23}$.

En base al histórico de subvenciones procedentes de la Agencia Española de Cooperación Internacional para el Desarrollo (AECID) ${ }^{24}$ entre 1992 y 2013, y destinadas a ONGs que han operado en Guinea Ecuatorial, se ha elaborado el siguiente cuadro resumen. En el mismo se ordenan las entidades beneficiadas según los importes recibidos de la AECID en este periodo de tiempo. Asimismo, se señalan los sectores

23 En base al tipo de convocatoria (proyectos, programas, convenios) el pago de algunas subvenciones se desglosa sobre varios años por lo que no solo se registran los años de adjudicación de las subvenciones, sino todos aquellos en los que se ha percibido financiación, es decir durante los cuales las ONG han gestionado fondos públicos procedentes de la AECID.

24 El nombre original de esta entidad fue la Agencia Española de Cooperación Internacional (AECI). Fue modificado en 2007 cambiando su nombre por el actual. 
de intervención a los que se han destinado los fondos de las subvenciones y los años en los que cada estructura ha percibido fondos.

El seguimiento de las subvenciones de la AECID a las ONG operando en Guinea Ecuatorial desde 1992 hasta 2013 ilustra el destacado lugar que ocupan las organizaciones confesionales. Los sectores más subvencionados son los de educación $(54.657 .321,36 €)$ y salud $(30.380 .261,06 €)$. Las entidades más beneficiadas han sido con diferencia, FERE (52.253.220,45 €) y FRS (25.067.300,49 €), entidades coordinadoras de la acción misionera en educación y salud en Guinea Ecuatorial. Han gozado del apoyo de la cooperación de forma casi ininterrumpida en este periodo. 56 de las 96 subvenciones han sido otorgadas a una de las dos entidades. Concentran más del 85,65\% (77.320.520,94€) de los fondos destinados al país $(90.275 .998,30$ $€)$. Asimismo, se señalan con un asterisco (*) las subvenciones que si bien no han sido concedidas directamente a alguna de las dos organizaciones, han sido otorgadas a entidades de inspiración cristiana vinculadas a estas mismas entidades, y en beneficio de las mismas, para la implementación de sus servicios e infraestructuras. Concentrarían por lo tanto a lo largo de los últimos 20 años casi el $90 \%$ de las subvenciones del Estado español destinadas a las ONG que intervienen en el país.

La fidelidad de la financiación de la AECID con las congregaciones religiosas que operan en el ámbito sanitario en Guinea Ecuatorial se ha traducido en más de un millón de euros de media al año en los últimos 20 años. En 1994, el argumento humanitario esgrimido por la cooperación española para "redimensionar" su intervención, velaba por un apoyo selectivo a los proyectos y a las ONGs identificadas para encarnarlo, privilegiando las entidades de carácter confesional. Los religiosos, iconos de un particular compromiso moral hacia la alteridad, parecían encarnar a la perfección la preocupación "humanitaria" del Estado español 25.

La dimensión simbólica de las labores religiosas, así como la fuerza política de las redes cristianas son probablemente el motivo de la reconducción sistemática de las subvenciones de la AECID a las congregaciones. Según algunos cooperantes españoles de la época, la FERS ni tan siquiera estaba sujeta hasta 1999, a la formulación y presentación de proyectos para la obtención de las subvenciones.

Por otra parte, los nuevos paradigmas de la cooperación internacional pretendían, o escenificaban, la participación de la sociedad civil del país receptor. El modelo implementado asocia la ONG del norte, receptora de la subvención, con una del sur, denominada "contraparte local". La primera aporta los recursos técnicos y monetarios para la realización de las acciones seleccionadas, mientras la segunda aportaría la experiencia y arraigo local necesario para el éxito de la intervención. Si bien FERS ha sido la ONG adjudicataria de las subvenciones, las congregaciones religiosas es-

25 Otras organizaciones, como Médicos Sin Fronteras (MSF), que venía trabajando en ámbitos similares durante los años noventa, no lograría durante el tiempo que permanecieron en el país ni tan siquiera una décima parte de los fondos destinados a las congregaciones por el mismo periodo. MSF abandonaría el país en octubre de 1999. En un informe publicado al final del mismo año, otorga un claro significado político a su retirada. Define Guinea Ecuatorial como "un espacio humanitario imposible" en el que según la organización, las autoridades obstaculizarían en permanencia su labor. MSF aprovecharía su reciente notoriedad (la organización acababa de recibir el Premio Nobel de la Paz) para denunciar las relaciones mantenidas por España "con un régimen que desprecia absolutamente las necesidades de su población y viola sistemáticamente sus derechos" (MSF, 1999). MSF, cuya legitimidad radica en parte en la denuncia - mientras las congregaciones religiosas fundamentan la suya en la dimensión compasiva de la intervención_, ilustran una movilización diferencial de lo humanitario. Si MSF pretende situar su acción y discurso en el tablero político, la cooperación española construye, mediante su apoyo a las congregaciones, un enunciado "humanitario" que pretende desvincularse de la política. 
pañolas han representado durante años la "contraparte local" del esquema, substituyéndose a los organismos del país receptor de la ayuda. Este puenteo no parece haber incomodado a sus financiadores. Traduce la voluntad manifiesta de sortear las dificultades ligadas a la cooperación con el Estado guineano, privilegiando unidades sanitarias privadas. Solo a partir del 2007, la formulación de los proyectos de FRS en Guinea Ecuatorial contemplaría directamente al Ministerio de Sanidad ecuatoguineano como "contraparte local".

\section{Los centros de salud confesionales en el mercado formal de la salud}

\subsection{Archipiélagos sanitarios}

En 2011, llevé a cabo una investigación etnográfica en diferentes espacios de terapia en Bata. Puso en evidencia que entre los diferentes recursos existentes en contexto urbano, los centros de salud confesionales se encontraban entre las alternativas mejor valoradas por la población. Los criterios de apreciación destacados por los usuarios regulares y ocasionales interrogados recalcan las ventajas comparativas de los centros confesionales en torno a la relación calidad/precio. Inciden en la relativa accesibilidad económica, la calidad de la acogida, la disponibilidad de medicamentos, la rapidez de los resultados de las analíticas, y la claridad del itinerario en el seno de los centros. También cabe recalcar, que fruto del éxito de los centros confesionales, las principales quejas aluden a los largos tiempos de espera ligados a la afluencia de enfermos (Jones Sánchez, 2016: 135-149).

La competitividad de las alternativas confesionales no se puede desvincular de los medios económicos y materiales de los que disponen y, en última instancia, del capital simbólico de las congregaciones para la obtención de subvenciones. Sus centros se caracterizan por el buen estado de las infraestructuras y equipamientos, y el suministro regular de luz y agua. También gozan de canales de suministro de medicamentos estables. Las hermanas de San José del centro de salud de $\mathrm{M}^{\mathrm{a}}$ Gay en Bata tienen su propia central de compras. Abastecen en prioridad los demás centros confesionales $^{26}$ antes que los servicios del Estado. A diferencia de las estructuras públicas, que no disponen de una central de compras unificada, los centros confesionales tienen escasísimas rupturas de stock y ofrecen los precios más competitivos en el mercado formal del medicamento. La disponibilidad de medicamentos es un elemento importante en la valoración y utilización de los centros, ya que permite a los usuarios recurrir a una sola estructura para la consulta y la compra de los fármacos recetados, eludiendo los costes y tiempos que conlleva el recorrido por diferentes proveedores. En algunos centros no-confesionales, la disponibilidad o no de medicamentos marca periodos de mayor o menor afluencia.

La mayor disposición de recursos materiales, financieros y humanos también impacta en la motivación y compromiso del personal sanitario. El contexto de trabajo generado en los centros confesionales (así como en otras estructuras privadas) se asimila a pequeñas isletas en las que no se reproducen las condiciones laborales que rigen los espacios sanitarios públicos. Los sanitarios no han de lidiar con la

26 Excepto el centro confesional de $\mathrm{M}^{\mathrm{a}}$ Rafols en Bata que dispone también de su propio suministro seguro. 
frustración y el desgaste ligados a la escasez de insumos médicos, el deterioro del equipamiento, la falta de medicamentos o la deserción sistemática de algunos de sus compañeros. También cabe señalar que los profesionales que operan en los centros confesionales o en sus áreas de influencia se han beneficiado, especialmente estos últimos años, de formaciones continuas financiadas por la cooperación española.

Por otra parte, impera en el sector público una cultura laxista con la falta (la desviación de fondos, el absentismo, el descuido del paciente,) que raras veces desemboca en medidas disciplinarias (Jones Sánchez, 2016: 44; 111-123). En los espacios regidos por las religiosas, la mayoría del personal contratado no depende de la función pública. Es empleado por las propias estructuras privadas, y sujeto a mecanismos de gestión y supervisión más estrictos. Estos elementos singularizan al personal afectado a los centros de salud privados en relación a los demás funcionarios. El cumplimiento con un marco ético y moral constituye, para los trabajadores de las alternativas privadas, una estrategia, una inversión a largo plazo para el mantenimiento de un puesto de trabajo, con destacadas ventajas en relación al sector público (Jaffré, 2003: 327).

Frente a la oferta de los centros confesionales, la oferta pública se muestra claramente deficitaria. La experimentación de los diferentes espacios sanitarios, ha forjado las preferencias de los pacientes por estructuras mejor equipadas y a las que se les atribuye una atención de mayor calidad. Las relaciones de confianza y desconfianza respecto a un interlocutor sanitario u otro, se han fraguado en un recorrido histórico determinado. Los centros de las congregaciones religiosas son los únicos que desde cerca de veinte años no han visto afectados la continuidad, calidad y coste de sus servicios por las vicisitudes del contexto, gozando de una credibilidad de la que carecen otras entidades públicas, y especialmente los hospitales.

Gruénais (2007: 31) sostiene que los valores asociados a la acción misionera en el continente, constituirían un atractivo, un capital simbólico que participaría de su valoración positiva y altos índices de frecuentación. En el contexto guineano actual, la competitividad de los centros confesionales no radica tanto en los valores cristianos que animarían las religiosas españolas que los gestionan. Apela más bien a la disposición de los recursos necesarios para llevar a cabo una atención que cumple en gran medida con las expectativas de los usuarios. La producción de la calidad se sustenta en la disposición de recursos financieros y materiales de los que carece la oferta pública, y que permiten la reproducción de condiciones ideales, archipiélagos sanitarios sobre los que se asienta la identidad social de las congregaciones en el país. Si bien los valores cristianos y su vertiente compasiva no actúan en la actualidad como elementos catalizadores de la demanda de atención, esta dimensión simbólica de la identidad de las religiosas sí tiene especial relevancia para la captación de fondos procedentes de la industria del desarrollo española.

\subsection{Los efectos inopinados de una competitividad exitosa}

El sistema de salud guineano se disgrega en tres niveles. El primero se compone de los puestos de salud, el segundo de los centros de salud y el tercero corresponde a los hospitales. La intervención de las congregaciones religiosas españolas se ciñe en la actualidad al segundo nivel; gestionan 6 de los 44 centros de salud de Guinea Ecuatorial. 
Los 6 centros pertenecientes a las congregaciones son, con una salvedad, los más concurridos del país ${ }^{27}$. Según las cifras manejadas por la Fundación de Religiosos para la Salud (FRS), las seis estructuras de las religiosas atienden más consultas que los 38 centros restantes del país ${ }^{28}$. Ocupan por lo tanto un papel muy relevante en la oferta sanitaria institucionalizada. Incluyendo las consultas hospitalarias, sumarían en el 2010 más del $26 \%$ de todas las consultas del país ${ }^{29}$. La proporción sería aún más importante para los centros ubicados en las capitales de distrito ${ }^{30}$. El centro de salud Luis Amigó en Evinayong por ejemplo, administrado por las Hermanas Terciarias Capuchinas, acapara el 50\% de las consultas de la ciudad (FRS, 2013).

Estos datos dan cuenta de la importancia de las congregaciones religiosas españolas en el sistema sanitario guineano. La envergadura de su labor sanitaria es a menudo ensalzada, y sirve para justificar el apoyo financiero del que gran parte de las mismas se ha beneficiado por parte de la AECID.

Estas cifras también plantean aspectos más problemáticos. Ilustran el extremo grado de dependencia del sistema sanitario guineano respecto a las congregaciones. Por otra parte, la alta capacidad de atracción de los centros confesionales en relación con los centros públicos, pone de relieve la brecha existente entre la oferta privada, con flujos de financiación externos, y los servicios públicos del Estado guineano. Estos contrastes delinean una geografía sanitaria descompensada en torno a la presencia o no de la acción misionera. El promedio de consultas por habitantes es mayor en las zonas en las que están implantadas las religiosas españolas que en el conjunto del país (FRS, 2013). Toda la parte sur de la región continental del país, la parte oeste de la isla de Bioko, y el resto del territorio insular, no solo ha sido desatendida por la intervención misionera española, sino que también cuenta con las infraestructuras públicas más deficitarias del país.

En este sentido, cabe destacar que, a diferencia de las lógicas fundacionales de la acción misionera en otros países africanos, los centros confesionales no están situados en las zonas más desatendidas y difíciles de acceso desde el punto de vista sanitario $^{31}$. Las facilidades en términos logísticos, las posibilidades evangélicas o la disposición de las diócesis en cederles un espacio, se han impuesto sobre la voluntad de paliar el centralismo hospitalario y de facilitar el acceso a la atención sanitaria de las poblaciones más aisladas y necesitadas del país.

Otro de los aspectos problemáticos de la labor de los centros confesionales son las repercusiones de su destacada competitividad sobre los servicios del Estado. Si bien los centros confesionales están integrados en la red pública de salud, ${ }^{32}$ no se

27 El cuarto centro más concurrido del país es una estructura privada, gestionada por una ONG internacional (SOSKinderdorf International).

2842.461 consultas en el año 2010 en los 6 centros confesionales contra 41.124 en los 38 restantes (FRS, 2014).

29 Quedan excluidas en estas cifras las consultas de los equipos móviles de atención primaria y puestos de salud.

30 Es el caso de los centros de $\mathrm{M}^{\mathrm{a}}$ Rafols y M $\mathrm{M}^{\mathrm{a}}$ Gay y en Bata, los más concurridos del país, del centro Luis Amigó en Evinayong y del centro de salud de Angokong en Ebebiyin.

31 El centro Madre Alfonsina de Savín se sitúa en Sampaka en la periferia de la capital del país. Los dos centros confesionales más importantes están situados en el núcleo urbano de Bata. Uno de ellos incluso, el de $\mathrm{M}^{\mathrm{a}}$ Gay, se encuentra en las inmediaciones del hospital General de la ciudad. El eje Bata-Ebibeyin constituye, desde la época colonial, la parte más desarrollada y accesible de la parte continental del país. En el mismo se cuentan los dos centros de Bata ya mencionados, el centro de Mokom en el distrito de Mikomeseng y el de Angokong en el de Ebibeyin. El centro confesional más al sur se encuentra en la ciudad de Evinayong en el centro del país.

32 Si bien se trata de estructuras privadas, su integración en la red de centros públicos supone que deben cumplir con el paquete mínimo de servicios exigidos a los centros de salud por el Ministerio de Sanidad, que les sea asignada una zona de influencia y que parte de su personal dependa de la función pública. 
encuentran en situación de igualdad con las demás estructuras públicas pertenecientes a su mismo nivel de atención sanitaria. Su situación — privilegiada en términos financieros, materiales y humanos-, los hace sumamente más atractivos que las demás estructuras del sector público. En consecuencia, las entidades confesionales atraen pacientes procedentes de áreas sanitarias adjudicadas a otros centros de salud. Esta tendencia es especialmente marcada en contextos urbanos en los que los desplazamientos a una $u$ otra estructura sanitaria no suponen un incremento notable del gasto.

La ciudad de Bata es especialmente paradigmática en este sentido. Las dos estructuras de las congregaciones españolas ( $\mathrm{M}^{\mathrm{a}}$ Rafols y $\mathrm{M}^{\mathrm{a}} \mathrm{Gay}$ ) concentran más del 63\% de las consultas a los centros de salud de la ciudad (34\% y 29\% respectivamente). Otra estructura privada (SOS-Kinderdorf International), que también se beneficia de flujos de financiación externos, ocupa el tercer lugar en términos de afluencia (22\%). Los 3 centros públicos restantes alcanzan apenas el 15\% de las consultas del núcleo urbano, de los cuales, uno, también apoyado por la cooperación española (el centro la Libertad), congrega el 14\%. Los demás centros públicos, no logran afianzarse como alternativa en el área sanitaria que les corresponde. En otros términos, solo el 1\% de los pacientes de los centros de salud de la ciudad, acude a estructuras que no reciben financiación externa. Se advierte en este sentido una relación directa y proporcional entre la dotación económica externa, de la que benefician los centros privados confesionales, y la afluencia de pacientes. El acceso diferencial a la financiación externa determina la competitividad de cada estructura en el mercado de salud.

La polarización de la demanda esencialmente en torno a los centros confesionales no carece de consecuencias sobre los servicios de la oferta pública de salud. La financiación de las estructuras sanitarias del Estado se rige por mecanismos de autogestión ${ }^{33}$. Las partidas presupuestarias relativas a los gastos recurrentes dependen de los ingresos derivados de la tarificación de la atención prodigada al paciente (consulta, pruebas de laboratorio, insumos médicos y venta de medicamentos). La capacidad de cada estructura para asegurar el mantenimiento y la renovación de los equipos, así como el abastecimiento de la farmacia, están en este sentido directamente supeditados a la afluencia de pacientes. La población circundante al centro de Bome por ejemplo, ubicado en la periferia de la ciudad, prefiere desplazarse a las estructuras confesionales situados en el núcleo urbano. La falta de medios del centro orienta al paciente hacia otras alternativas. Asimismo, la falta de pacientes conlleva la imposibilidad de mantener y abastecer el centro adecuadamente. A pesar de los horarios establecidos por el Ministerio de Sanidad, el centro abre sus puertas apenas dos días a la semana según la disposición y motivación del personal sanitario asignado. El sistema de autogestión, según el cual la sostenibilidad de un centro de salud depende de la afluencia y contribución de los usuarios, propicia una situación en la que el funcionamiento de un centro puede participar del disfuncionamiento de otro.

El número de consultas es a menudo considerado un elemento de medición del éxito de los centros confesionales y ha sido un reclamo para el mantenimiento del flujo financiero procedente de la ayuda externa. La representación asistencial de la ayuda, evaluada exclusivamente por su capacidad de atracción de la demanda, ha

33 Este mecanismo de financiación promovido por la OMS en Bamako (1987), fue adoptado en Guinea Ecuatorial en la década de los noventa. 
obviado el impacto de las labores sanitarias de las congregaciones sobre la consolidación del sistema sanitario nacional.

\section{Definiciones encontradas de la ayuda}

\subsection{La reformulación reciente de la cooperación sanitaria española en Guinea}

Desde los años noventa, la mayor parte de la ayuda española al sector sanitario guineano ha sido orientada hacia las congregaciones religiosas. La intervención no ha participado del refuerzo y consolidación del sistema sanitario nacional, ni tampoco de su homogeneización. No obstante, varios indicios denotan en estos últimos años la voluntad de la cooperación española por alejarse de dinámicas asistencialistas y dotar la ayuda de un carácter más tecnicista, de cara a fortalecer las estructuras locales.

Dinámicas globales han participado de este cambio de rumbo. La cuestión de la eficacia que centralizó en los años noventa los debates en torno a las modalidades de la ayuda, culminaría con la Declaración de París en 2005 y su ratificación en la Agenda de Acción de Accra en 2008. Ambos marcos, suscritos por la cooperación española, abogaban por la apropiación y liderazgo del país receptor en aras de una cooperación más eficaz, orientada a la consecución de los Objetivos de Desarro1lo del Milenio. En esta línea, las nuevas orientaciones de la cooperación española tratarían de ajustarse con los lineamientos consensuados por la comunidad internacional $^{34}$. La AECID recogería, en su estrategia de intervención en el sector salud, la necesidad de apostar por "un enfoque que permita el fortalecimiento institucional de los sistemas nacionales de salud como eje fundamental" (MAEC, 2009: 4).

Por otra parte, el mantenimiento de modalidades de ayuda asistencialistas, orientadas a paliar la ausencia de medios financieros, en un contexto en el que el país receptor dispone desde finales de los noventa de abundantes recursos ligados a la explotación petrolífera, resultaba cada vez más insostenible. En consecuencia, la XI comisión mixta formada en 2009 por los estados español y guineano, pretendía precisamente reformular la ayuda. El documento firmado por ambas partes, privilegiaría la asistencia técnica, es decir la transmisión de conocimientos técnicos en detrimento de la movilización de fondos para infraestructuras e insumos en principio asumibles por el Estado guineano ${ }^{35}$.

En tercer lugar, la creciente incomodidad del Estado español no se puede desligar de las críticas emitidas por la prensa y los grupos de la oposición españoles, así como por diferentes organismos internacionales. La privatización de las rentas del crudo

34 Larrú, en base a al informe de seguimiento de 2009 sobre los avances realizados por los donantes respecto a la Declaración de París, recalca que España, si bien ha progresado respecto a 8 indicadores, ha empeorado en cuanto a la apropiación de prioridades de los socios y la elusión de estructuras paralelas de gestión" (Larrú, 2011: 7). El caso guineano, confirmaría esta apreciación.

35 Es difícil calibrar la naturaleza exclusivamente retórica o no de la posición entonces asumida por el Estado español. En el marco del convenio entre AECID y FRS ejecutado entre 2007 y 2012, se han llevado a cabo importantes desembolsos en infraestructuras, rehabilitación de puestos y centros de salud, y en equipamiento y suministros médicos. En todo caso, los recortes presupuestarios de la cooperación española a partir de 2011, motivados por la crisis que afectaría el espacio monetario europeo, ratificarían las disposiciones tomadas en el 2009 en cuanto a la limitación de los gastos de inversión. 
por las élites políticas del país y los escasos mecanismos de redistribución puestos en marcha han despertado, en numerosas ocasiones, la indignación internacional. Las denuncias también suelen recalcar las recurrentes violaciones de los derechos humanos en el país. En el ámbito de la cooperación sanitaria, las voces críticas recuerdan que tras más de 30 años de intervención directa en el sector, el sistema de salud del país sigue incipiente y en gran parte tributario de las religiosas españolas. En este contexto, el carácter obsoleto de la justificación "humanitaria", hacía cada vez más apremiante el cambio en las modalidades de la ayuda.

\subsection{De FERS a FRS}

La voluntad de la AECID por imprimir un nuevo rumbo a la cooperación en Guinea ha supuesto cambios importantes en aquellas organizaciones, que como la FERS, aspira a sus subvenciones. De hecho, la evolución de esta entidad, está estrechamente vinculada al recorrido de la cooperación española.

La FERS era un organismo confesiona ${ }^{36}$. Inició su recorrido en cooperación internacional en 1980, cuando las autoridades españolas solicitaron a la organización 40 religiosas con formación sanitaria, para intervenir en Guinea Ecuatorial. Más tarde, cuando a principios de los noventa la cooperación española delegó a las ONGs las intervenciones de desarrollo y ayuda humanitaria, la FERS permitiría sumar a los estatutos canónicos de las congregaciones, un paraguas jurídico desde el que concurrir a las convocatorias de subvenciones públicas. Inicialmente centradas en Guinea Ecuatorial, las intervenciones de la FERS en materia de cooperación internacional se extenderían a finales de los noventa a otras latitudes.

De cara a seguir adecuándose a los requisitos de la AECID, la FERS ha sido reconvertida en una organización civil. Rebautizada como Fundación de Religiosos para la Salud (FRS), asume desde 2008 la gestión y coordinación de los programas internacionales de desarrollo implementados por las congregaciones españolas en el sector sanitario.

Tal y como confiesa en 2012 el propio director de FRS en una entrevista a un periódico digital, la remodelación de la organización perseguía adecuarse a las exigencias de la AECID para poder seguir concurriendo a sus convocatorias ${ }^{37}$ (Poveda, 2012). Para ello, la nueva organización trataba de delimitar una separación entre la vertiente evangélica de la labor misionera, de aquella que se podría asociar al desarrollo. Desde los años noventa, la dimensión simbólica de la intervención de las congregaciones (fe, vocación, caridad, generosidad etc.) había resultado clave para la obtención de fondos públicos. Sería suplantada, o al menos difuminada años más tarde, en virtud del mismo objetivo, tras una dimensión más tecnicista.

Este desplazamiento del marco conceptual de la intervención, de la acción misionera hacia el desarrollo, se reflejaría en los estatutos de la nueva organización. A la adscripción eclesiástica de la anterior, que dependía administrativamente de la

36 La Federación de Religiosos Socio-sanitarios (FERS) ha sido una asociación de Derecho Pontificio, con personalidad jurídica propia. Estaba integrada por los Superiores Mayores de los Institutos religiosos y Sociedades de Vida Apostólica dedicados en España, parcial o totalmente, a actividades sanitarias y asistenciales relacionadas con el mundo socio-sanitario.

37 FRS permite a las congregaciones cumplir con los requisitos exigidos por los financiadores en términos de auditorías de cuentas, régimen de transparencia y experticia como ONG calificada en el sector salud (Poveda, 2012), requisitos imprescindibles para la obtención de una subvención de la AECID. 
conferencia episcopal, los nuevos enunciados estatuarios abogarían por el carácter civil de la fundación. A la formulación evangélica de los objetivos, relacionados con la caridad, la pastoral de salud y la enfermedad, se antepondrían fines laicos ligados a la solidaridad y a la "promoción de proyectos socio-sanitarios". Quedaba relegada en segundo plano la labor civilizadora por salvar las almas, a la que se le preferiría la formulación laica por atender los cuerpos.

\section{3. ¿Congregación versus cooperación?}

La marcada preferencia en los noventa de la cooperación española por privilegiar la labor de las religiosas, se inscribía en un intento por despolitizar la ayuda, destacando el carácter "humanitario" de su intervención. Poco más de una década después, bajo las presiones de la AECID, las nuevas estrategias implementadas por FRS, tratarían de secularizar la intervención, para adecuarla y situarla en la órbita de las políticas dominantes en materia de desarrollo.

En consonancia, el convenio ${ }^{38}$ concedido a FRS en 2007 por la AECID (por un monto de 9.500.000 de euros) adquiere por vez primera desde principio de los noventa, una dimensión más genérica. El objetivo esgrimido, "fortalecimiento institucional del sistema de salud" del país, manifiesta la voluntad por desanclar la intervención más allá de los servicios prodigados por las congregaciones, e implementar dinámicas orientadas hacia la "autonomización" y "sostenibilidad" 39 del sistema público de atención primaria. El marco discursivo resignificaba nuevamente la intervención, desplazándose de la dimensión humanitaria y asistencial desarrollada al margen de las políticas nacionales, hacia el espacio político en el que se gestan las estrategias nacionales de salud.

La voluntad de superar una perspectiva asistencialista de la intervención se ha visto enfrentada a diversos obstáculos ligados a los intereses divergentes de las instituciones involucradas. En primer lugar, cabe recalcar, si no la oposición, al menos la tensión entre el objetivo manifiesto de FRS de garantizar que las congregaciones "puedan tener acceso a los fondos [públicos] de ayuda a la cooperación y el desarrollo" ${ }^{40}$, y los fines esgrimidos por FRS ante la AECID, que sitúa el conjunto del sistema sanitario nacional como el principal beneficiario de la intervención.

La intervención iniciada por FRS en 2007 ilustra algunas de las manifestaciones más recientes de esta contradicción. A pesar del giro "global" imprimido a su intervención, no lograría desligarse de los intereses de las congregaciones, que constituyen el motivo de la presencia de la organización en el país. La intervención seguiría centrándose casi exclusivamente en las zonas con presencia de las religiosas, participando de la ya mencionada descompensada geografía sanitaria ${ }^{41}$.

En el 2009, la Dirección Nacional de Atención Primaria se opuso por primera vez al proteccionismo de la red de centros confesionales. En vísperas del nombramiento

38 En el marco de las diferentes modalidades de financiación de la AECID, la más ventajosa en cuanto a los montos adjudicados y tiempos otorgados para la ejecución de las actividades, es la que se denomina convenio. Se suscriben convenios, generalmente de 4 años, entre la AECID y la ONG beneficiaria para cada uno de los proyectos objeto de subvención.

39 Según los términos utilizados en la formulación del proyecto.

40 Así lo expresaba el director de FRS en la entrevista realizada en el 2012 anteriormente citada (Poveda, 2012).

${ }_{41}$ "Ellos solo miran por sus áreas de influencia — señalaba una responsable del Ministerio de Sanidad y Bienestar Social de Guinea Ecuatorial (MINSABS) — nosotros tenemos que velar por el país". 
anunciado de agentes de salud por el gobierno guineano, FRS diseñó un programa de formación destinado exclusivamente para los agentes de salud procedentes de sus áreas de influencia. Tras varios meses de contencioso, el Ministerio de Sanidad logró que FRS llevase a cabo la formación a nivel nacional. En el 2011, se repitió el mismo desencuentro y correspondiente desenlace en relación con una formación destinada a los técnicos laboratoristas de los centros de salud. A pesar de estas contadas victorias del Ministerio, la mayor parte de las formaciones impartidas por FRS y financiadas por la AECID entre 2007 y 2012, han sido destinadas al personal sanitario operando en las zonas de influencia de FRS.

La implementación de los procesos de delegación promovidos por la nueva intervención, también han resultado problemáticos.Por ejemplo, una de las metas del convenio estipulaba que la totalidad del personal local contratado por FRS debería pasar a la función pública al finalizar el mismo. Un objetivo fallido pues en los centros de Mokom y $\mathrm{M}^{\mathrm{a}}$ Gay por ejemplo, ya que solo el $14,3 \%$ y $36,4 \%$ (respectivamente) del personal sanitario era asumido por la función pública (FRS, 2013: 77).

Las resistencias del Estado guineano en asumir responsabilidades no se pueden desvincular del carácter sustitutorio de la intervención de FERS/FRS en los últimos 30 años y de la inercia generada en consecuencia. Por otra parte, las rentas del petróleo no se han traducido en una implicación mayor del Estado guineano en la implementación y la gestión de salud pública. Las dotaciones presupuestarias orientadas al sector sanitario, han sido esencialmente destinadas a la edificación de estructuras privadas, equipadas de alta tecnología, que participan de la estrategia de visibilización del Estado guineano en el escenario internacional, pero sin repercusiones substanciales en el funcionamiento de las estructuras públicas.

Los centros confesionales por su parte, atienden a lógicas e intereses que no necesariamente coinciden con los del Ministerio de Sanidad ni con las estrategias diseñadas por FRS y la AECID. Tampoco pretenden que todo su personal sea asumido por el Ministerio de Sanidad, contraviniendo uno de los resultados estipulados por FRS. Se resisten a impulsar procesos de delegación e ignoran en ocasiones los protocolos y directrices nacionales ${ }^{42}$.

Los paradigmas que marcan desde los años noventa las políticas de desarrollo, suscritos por la AECID, postulan un apoyo provisional de la ayuda externa, capaz de encarrilar, promover y reforzar el funcionamiento autónomo de las instituciones locales. Las congregaciones por su parte, movilizan otras acepciones de la ayuda ${ }^{43}$, cuya valoración no se expresa tanto en la capacidad para impulsar mecanismos de empoderamiento, sino en su dimensión asistencial y curativa.

Cabe preguntarse sobre las posibilidades de fortalecer un sistema sanitario desde fuera, a través de agentes, las congregaciones, cuyas prioridades no están directamente ligadas a dicho objetivo. La conciliación de los modelos de desarrollo promovidos por la AECID y su apoyo a las congregaciones religiosas, traduce las

42 Por ejemplo, los precios de las consultas, estipulados por el Ministerio de Sanidad, oscilan de un centro confesional a otro. En algunos casos, los equipos móviles de los centros, como en Ebibeyin, trascienden por iniciativa propia las áreas geográficas que les corresponden alegando, lo que también es cierto, que los servicios públicos desatienden aquellas zonas.

43 Una responsable de uno de los centros más importantes del país manifestaba así la especificidad de las congregaciones en el panorama de la cooperación: "Nosotras, las hermanas que hemos venido aquí, lo que hacemos no es como cualquier puesto de trabajo de cooperación. Hemos creado raíces. Vivimos aquí. Entonces, con otro tipo de estrategia estamos ayudando al país". 
ambigüedades de las políticas de España con Guinea. En las mismas se manifiesta la voluntad por conciliar intereses geoestratégicos, exhibir ideales humanitarios, y adecuarse a los paradigmas actuales en materia de cooperación al desarrollo. La conjunción de intereses dispares da cuenta de la distancia entre los objetivos planteados y los resultados alcanzados. Según los evaluadores de la intervención coordinada por FRS y financiada por la AECID entre 2007 y 2012, la consecución de los resultados esperados alcanzaría menos del $40 \%{ }^{44}$, siendo la vertiente ligada a la asistencia la más exitosa, y aquella ligada al refuerzo institucional la más problemática ${ }^{45}$.

El argumento invocado por el Estado español en 1993 para retirar la ayuda a los hospitales y mantener el apoyo a las congregaciones, apelaba a la supresión de "aquellos programas de carácter sustitutorio". Aludía entonces al desempeño de la cooperación española de servicios que incumbían al Estado guineano. En 2013, 20 años más tarde, la intervención de FRS y las congregaciones es curiosamente calificada de "sustitutoria" por sus evaluadores (FRS, 2013: 121, 125 y 127).

\section{Conclusión: el sempiterno debate en torno a la AOD (Ayuda Oficial al Desarrollo) española en Guinea Ecuatorial}

Es innegable que los centros de salud confesionales ofrecen servicios sanitarios de primera necesidad ${ }^{46}$ que el Ministerio de Sanidad, por falta de medios y voluntad política se resiste a asumir. Las congregaciones se han abierto camino en un contexto marcado por la ausencia de interventores estatales en materia sanitaria. La falta de medios en el contexto de los ochenta, y la falta de voluntad política del Estado guineano en las décadas siguientes, supusieron una oportunidad fundacional para las congregaciones religiosas españolas. Con el paso del tiempo el desentendimiento del Estado en materia de salud pública las ha situado en un lugar de referencia en el paisaje sanitario del país.

Cabría preguntarse si al mismo tiempo que el sector confesional ha suplido un vacío imputable a la falta de implicación del Estado, no ha participado simultáneamente de la reproducción del desentendimiento de las élites políticas respecto al sector sanitario público. En este sentido, las voces más críticas aseguran que la ayuda española al desarrollo habría si no alentado, al menos facilitado al régimen, la escasa

44 Según se puede leer en la evaluación, "se han alcanzado pocas de las metas propuestas, en conjunto un 37,5\% en el caso de los objetivos y un 34,5\% en el de los resultados. Con un $75 \%$ de actividades realizadas, la eficacia ha sido francamente baja" (FRS, 2013: 123)

45 La consecución problemática de los resultados no ha impedido que la cooperación española haya reiterado su confianza en FRS. La fundación se ha beneficiado de la convocatoria de convenios de la AECID para Guinea Ecuatorial para el periodo 2014-2017 por un monto de 2.500.000 €. Algunas voces apuntan que se trataría de la última convocatoria de la AECID destinada a la cooperación en el país. El diseño del nuevo proyecto, atendiendo a las críticas y evaluaciones pasadas, está exclusivamente orientado hacia el refuerzo del sistema central. Según consultores de la organización, en el marco del mismo, se habría propuesto a las congregaciones religiosas la delegación del funcionamiento de sus centros privados a las autoridades sanitarias nacionales, de aquí hasta el final del nuevo convenio. Algunos, probablemente alentados por la edad avanzada de las hermanas y la falta de relevo vocacional, habrían accedido. Otros centros, al menos dos, se habrían negado rotundamente, manteniendo la postura proteccionista que han defendido a lo largo de su recorrido en el país.

46 La disminución de la tasa de mortalidad infantil estos últimos años, no se puede desvincular de las labores de FRS. 
implicación en la implementación del sistema sanitario público y de los servicios sociales de forma más genera ${ }^{47}$.

Protagonicé en 2011 un curioso incidente a lo largo de un coctel ofrecido por el consulado español de Bata en ocasión de la visita del entonces presidente del congreso de los diputados, J. Bono. Expresé al mandatario español, en base a mi experiencia en una organización internacional de cooperación en el país, mis reservas en cuanto a los resultados, en mi opinión discutibles, de la cooperación sanitaria española en el país, en relación al tiempo (30 años) y fondos invertidos. Si bien el mandatario eludió hábilmente la pregunta, fui muy rápidamente increpado por la que era entonces la responsable de FRS. Entre improperios, señaló que a ella "sí [le] importan los niños que mueren en Guinea".

Más allá del carácter trivial de la anécdota, y de la postura que entonces manifesté, el suceso ilustra el sentido compasivo otorgado al sector salud, como una dimensión moral superior que no admite y excluye de su campo cualquier perspectiva crítica. Los significados de la acción sanitaria, como señala Fassin (2000: 28), suelen generar tal consenso que tienden con frecuencia a eludir cualquier mecanismo interpretativo.

En términos más amplios, el altercado traducía también el sempiterno debate en torno a la ayuda extranjera en Guinea. Por una parte, aquellos que consideran que la ayuda al desarrollo ha de estar condicionada a ciertas garantías del Estado guineano en términos de derechos humanos, apertura y alternancia democrática y redistribución de la riqueza, tareas sobre las cuales se han realizado escasos avances en los últimos 30 años $^{48}$. Por otra parte, aquellos que consideran, (como mi interlocutora circunstancial,) que la ayuda, especialmente en el campo sanitario, es un imperativo moral y apolítico, participe o no de la consolidación del régimen dictatorial. La primera postura apela a los derechos humanos, es decir aquellas normas y valores que según el derecho internacional, están destinados a promover y proteger las libertades y garantías indiviudales del ser humanospara su desarrolllos. La segunda tiende más bien hacia el derecho humanitario (generalmente asociado a situaciones de conflicto), esto es, al imperativo de la intervención para salvar vidas.

La dialéctica humanitaria es la que de forma global, ha prevalecido en relación con Guinea Ecuatorial a lo largo de los últimos 35 años. Erige de forma ontológica el dolor, el sufrimiento y la muerte como principal prisma de lectura. Fassin (2000: 22; 2006: 45) la denomina biolegitimidad, es decir el ideal ético, inherente a la acción humanitaria contemporánea, en el que predomina el reconocimiento de los cuerpos físicos, alterados o afectados por la enfermedad, antes que el de las personas. Si bien esta perspectiva se sitúa a sí misma fuera del ámbito político, permanece en su órbita. En primer lugar, porque tiende a desactivar el significado político de la historia de la ayuda con Guinea Ecuatorial. La intervención ha ofertado una vertiente moral a la presencia española en Guinea, desde que en 1980, la antigua colonia volviese a aparecer como un espacio de alto interés geoestratégico. En segundo lugar, porque, en virtud de la urgencia humanitaria, prevalece la vida de algunos sobre los derechos de muchos. Cabe preguntarse, como lo hace Brukner (1996: 273), si la intervención

47 Véase por ejemplo Campos Serrano (2011), y Larrú (2010, 2011).

48 Una postura hoy caduca debido a la independencia financiera que ha adquirido el país respecto a la ayuda, en base a la explotación petrolífera; pero cuyos planteamientos aún son extrapolables a los apoyos occidentales en términos políticos y comerciales que legitiman el régimen. 
humanitaria no lleva, en ocasiones, a "descuidar algunos pueblos fingiendo prestarles auxilio".

\section{Referencias bibliográficas}

Abaga Edjang, Fernando (1997). La Ayuda Externa en el desarrollo de Guinea Ecuatorial. Madrid: La Catarata.

Berche, Thierry (1985). “À propos d’une ONG de développement sanitaire: 1‘Église catholique en Afrique et les soins de santé primaires ". Sciences sociales et santé, vol. 3, n 3-4 : 85-103.

Blanco Moro, Agustín (1997). Memorias del Sur: recuerdos africanos de un salubrista. Malaga: Seyer.

Bruckner, Pascal (1996). La tentación de la inocencia. Barcelona: Anagrama.

Castillo-Rodríguez, Susana (2013). Colonizando lenguas: misiones y la política del español en Guinea Ecuatorial. Tesis doctoral. The City College of New York.

Campos Serrano, Alicia (2005). Ayuda, mercado y buen gobierno: los lenguajes del desarrollo en África en el cambio de milenio. Barcelona: Icaria Editorial.

- 2011. "Petróleo y Estado postcolonial: transformaciones de la economía política en Guinea Ecuatorial, 1995-2010. Implicaciones para la coherencia de políticas españolas". Avances de Investigación 54. Madrid: Fundación Carolina.

Centro por los Derechos Económicos y Sociales (CDES) (2009). "Guinea Ecuatorial: Visualizando los derechos", Ficha informativa núm. 9.

Creus, Jacint (2007). "Cuando las almas no pueden ser custodiadas: el fundamento identitario en la colonización española de Guinea Ecuatorial”. Hispania Nova, Revista de Historia Contemporánea. vol. LXVII, no 226, mayo-agosto: 517-540.

Diario de Sesiones del Congreso de los Diputados (1994). Comisiones, V legislatura, num. 105, del miércoles 9 de febrero. (http://www.congreso.es/public_oficiales/L5/CONG/DS/ CO/CO_105.pdf)

Duriez, Bruno; Mabille, François; Rousselet, Kathy (Coords.) (2007). Les ONG confessionnelles. Religions et action internationale. Paris : L'Harmattan, 9-22.

Fassin, Didier (2000). "Entre politiques de la vie et politiques du vivant. Pour une anthropologie de la santé". Anthropologie et Sociétés, 24, 1: 95-116.

— 2006. "Le biopolitique n'est pas une politique du vivant". Sociologie et sociétés, vol. 38 $\mathrm{n}^{\mathrm{0}} 2: 35-48$.

Fountain, Philip (2013). " Le mythe des ONG religieuses : le retour de la religion dans les études du développement". Revue internationale de politique de développement, 4. DOI : 10.4000/poldev.1302 (http://poldev.revues.org/1302)

Fundación de Religiosos para la Salud (FRS) (2013). Informe de Evaluación final: Convenio AECID-FRS CO1-010-01, a cargo de Eguíluz Fernández de Valderrama R., y Fernández Costales J.J. (http://fundacionfrs.es/files/Informe $\% 20$ final $\% 20 \mathrm{de} \% 20$ evaluaci $\%$ C3\%B3n\%20convenio\%20AECID $\% 20 \mathrm{FRS} \% 20$ Guinea $\% 20$.pdf).

- 2014. Cifras y estadísticas de la línea de base elaborado por Ramiro Eguiluz Fernández de Valderrama. No públicado.

Gorozpe, Iñaki (1994). “Guinea Ecuatorial: Radiografía de una dictadura”. África - América Latina Cuadernos, ${ }^{\circ}$ 14: 73-82.

— 2006. "Guinea Equatorial: crecimiento sin desarrollo". Cuadernos Bakeaz 75.

Gruénais, Marc-Éric (2004). “ Les qualités de l'offre de soins confessionnelle en Afrique subsaharienne ". Autrepart, n 29 : 29-46. 
Haynes, Jeffrey (2013). “ Les organisations confessionnelles, le développement et la Banque mondiale ". Revue internationale de politique de développement 4. DOI : 10.4000/ poldev.1310 (http://poldev.revues.org/1310).

Hovland, Ingie (2008). "Who's afraid of religion? Tensions between 'mission' and 'development' in the Norwegian Mission Society” en Clarke G., y Jennings, M., (eds.) Development, Civil Society and Faith-Based Organizations: Bridging the Sacred and the Secular, Basingstoke and New York: Palgrave Macmillan: 171-186.

Jaffré, Yannick (2003). “La configuration de l'espace moral et psychologique des personnels de santé ” : en Jaffré Y. y J.-P. Olivier de Sardan (Eds.), Une médecine inhospitalière. Les difficiles relations entre soignants et soignés dans cinq capitales d'Afrique de l'Ouest. Paris: Karthala, 295-337.

Jones Sánchez, Alvar (2013). “Saberes, percepciones y modalidades de uso de los recursos terapéuticos en Bata, Guinea Ecuatorial", en Aranzadi Martinez J. \& Moreno Feliú, P. (Eds.), Perspectivas Antropológicas sobre Guinea Ecuatorial, Madrid: UNED, 101-134.

- 2016. Marcos formales, recorridos informales: las lógicas del consumo terapéutico en Guinea Ecuatorial. Tesis doctoral. Facultad de Humanidades de Toledo. Universidad de Castilla-La-Mancha.

Kaag, Mayke; Saint-Lary, Maud (2011). “ Nouvelles visibilités de la religion dans l'arène du développement". Bulletin de l'APAD 33 (http://apad.revues.org/4073).

Larrú, José María (2011). "Más ¿es mejor? Reflexiones en torno a la calidad de la ayuda al desarrollo española". Revista de economía mundial, n²2: 205-245.

- 2010. Foreign Aid in Equatorial Guinea: Macroeconomic Features and Future Challenges. MPRA, Paper 25001, University Library of Munich, Germany. (http://mpra. ub.uni-muenchen.de/25001/)

Lautier, Bruno (2001). “ Sous la morale, la politique. La banque mondiale et la lutte contre la pauvreté ". Politique Africaine, n82: 169-175.

Médicos sin Fronteras (MSF) (1999). “Guinea Ecuatorial: El espacio humanitario imposible”, Dossier Diciembre, MSF.

Ministerio de Asuntos Exteriores y de Cooperación (MAEC) (2009). Plan de actuación sectorial de salud vinculado al III Plan Director.

Nerín, Gustau (2008). Un guardia civil en la selva, Barcelona: Ariel.

- 2011. Blanco bueno busca negro pobre, Una crítica a los organismos de cooperación y a las $O N G$, Barcelona: Roca editorial.

Organización Mundial de la Salud (OMS) (2006). Appreciating Assets: Mapping, Understanding, Translating and Engaging Religious Health Assets in Zambia and Lesotho.

Picas Contreras, Joan (2001). El papel de las organizaciones no gubernamentales y la crisis del desarrollo. Una crítica antropológica a las formas de cooperación. Tesis doctoral. Departamento de Antropología Cultural e Historia de América y África. Universidad de Barcelona.

— 2006. "Los límites de la solidaridad: las ONG y el mercado de "bienes simbólicos". Gazeta de Antropología n²2, artículo 8. (http://hdl.handle.net/10481/7086)

Poveda, Javier. Entrevista en el diario Periodista Digital del 10 de abril de 2012. ( http:// www.periodistadigital.com/religion/solidaridad/2012/04/10/religion-iglesia-fundacionreligiosos-salud-javier-poveda-cooperacion-misioneros-congregaciones.shtml)

Pozuelo Mascaraque, Belén (1991). "La política española de Cooperación al Desarrollo del África Subsahariana”. Cuadernos de Historia Contemporánea, vol.13: 205-220.

Roig, Joan (1993). "España y la transición política en Guinea Ecuatorial”. Hacia un cambio en África, $\mathrm{n}^{\circ} 17$. 
Vilaró i Güell, Miquel (2009). "Los avatares de la primera expedición misionera a las posesiones españolas del Golfo de Guinea a cargo de los eclesiásticos ilustrados Jerónimo Mario Usera y Alarcón y Juan del Cerro". Hispania Nova, Revista de Historia Contemporánea, $\mathrm{n}^{\circ}$ 9. (http://hispanianova.rediris.es/9/articulos/9a002.pdf)

- 2010. El legado de los jesuitas en Guinea. Ceiba ediciones. 2010. 